\title{
CAPÍTULO 10: A IMPORTÂNCIA DA AGRICULTURA FAMILIAR NA ATUALIDADE
}

\section{CHAPTER 10: THE CURRENT IMPORTANCE OF FAMILY AGRICULTURE}

\author{
Maria Madalena Bertolini ${ }^{1}$; Pedro Luiz Paula Filho ${ }^{2}$; Saraspathy Naidoo Terroso Gama de Mendonça ${ }^{3}$
}

\begin{abstract}
Resumo
Nos anos sessenta, o Brasil estimulou a mecanização sem limites, ofertando linhas de crédito, apoiando a agricultura de grande extensão. A agricultura de subsistência, foi negligenciada em favor da produção de exportação. Com a preocupação mundial em torno da preservação da biodiversidade e evitar-se o prejuízo aos recursos naturais, várias instituições têm demostrado interesse em fortalecer a agricultura familiar, como forma de sustentabilidade ambiental, segurança e soberania alimentar. Este estudo bibliográfico almeja apontar a importância da agricultura familiar e seus gargalos, e motivar a reflexão sobre a priorização de políticas públicas. A Assembleia Geral das Organizações das Nações Unidas destaca a Década da Agricultura Familiar de 2018 a 2029, chamando atenção a esta categoria de produtores, desamparados e responsáveis por $80 \%$ dos alimentos produzidos no mundo. Observa-se que os setores públicos precisam priorizar e elaborar políticas públicas quanto à linhas de crédito para modernizar e fortalecer os pequenos produtores, viabilizar assistência técnica, acesso às tecnologias e incentivo às mulheres e aos jovens, para melhorar o seu nível de estudo, apoiando-os na permanência no campo. Sem dúvida, a agricultura familiar é a atividade de produção essencial para alimentar a população mundial, bem como propiciar às futuras gerações, um meio ambiente preservado.
\end{abstract}

Palavras-Chave: Desenvolvimento, Alimentação, Biodiversidade, Agricultores.

\begin{abstract}
In the sixties, Brazil stimulated mechanization without limits, offering credit lines, supporting large-scale agriculture. Subsistence agriculture was neglected in favor of export production. With the worldwide concern around the preservation of biodiversity and the avoidance of damage to natural resources, several institutions have shown interest in strengthening family farming, as a way of environmental sustainability, security and food sovereignty. This bibliographic study aims to point out the importance of family farming and its bottlenecks, and to motivate reflection on the prioritization of public policies. The General Assembly of United Nations Organizations highlights the Decade of Family Farming from 2018 to 2029, drawing attention to this category of producers, destitute and responsible for $80 \%$ of the food produced in the world. It is observed that the public sectors need to prioritize and elaborate public policies regarding lines of credit to modernize and strengthen small producers, provide technical assistance, access to technologies and encourage women and young people to improve their level of study, supporting them while staying in the field. Undoubtedly, family farming is the essential production activity to feed the world population, as well as to provide future generations with a preserved environment.
\end{abstract}

Keywords: Development, Food, Biodiversity, Farmers.

\footnotetext{
${ }^{1}$ Programa de Pós Graduação em Tecnologias Computacionais para o Agronegócio, Universidade Tecnológica Federal do Paraná-MD, madalenabertolini@hotmail.com

${ }^{2}$ Programa de Pós Graduação em Tecnologias Computacionais para o Agronegócio, Universidade Tecnológica Federal do Paraná-MD, pedrol@utfpr.edu.br

${ }^{3}$ Programa de Pós Graduação em Tecnologias Computacionais para o Agronegócio, Universidade Tecnológica Federal do Paraná-MD, naidoo@ufpr.edu.br
} 


\section{Introdução}

A agricultura familiar é de grande importância social e econômica, responsável pelo abastecimento de alimentos no Brasil e no mundo. Esta importante parcela de trabalhadores rurais foram excluídos das políticas de desenvolvimento elaboradas para a produção das grandes propriedades, e sofrem com a demanda da competividade e desafios da globalização (DOS SANTOS; MITJA, 2016). Outro dilema é a crescente dependência e uso das tecnologias na agricultura, fato que impõe um fardo às pequenas propriedades, por falta de recursos e de assistência técnica. Ressalta-se que os agricultores apresentam baixa escolaridade, o que dificulta o uso das Tecnologias de Informação-TIs (DEPOINTI, 2014).

Nações Unidas- ONU, lançou de 2019 a 2028 um programa intitulado como a Década das Nações Unidas para a Agricultura Familiar, com o objetivo de impulsionar a elaboração de políticas públicas que promovam o desenvolvimento permitindo a sustentabilidade e a preservação do meio ambiente (DA SILVA, 2019). Neste sentido o Comitê Gestor da ONU, aprovou o Plano de Ação Global da Década, para que posteriormente cada país elabore o seu Plano. Desta forma, oportuniza discussões sobre a realidade, as necessidades e a importância da agricultura familiar, que tanto contribui para a alimentação no mundo (FRATARI; DA SILVA, 2019).

Um aspecto fundamental da agricultura familiar é a produção de alimentos saudáveis, utilizando práticas que não agridem o meio ambiente e a biodiversidade e a saúde, aumentando a produtividade, de modo a alimentar quase 10 bilhões de habitantes no mundo até 2050. A agricultura familiar é essencial para se alcançar a segurança alimentar no mundo.

O Brasil tem se destacado com as políticas de incentivo ao pequeno produtor com a criação do Programa Nacional de Fortalecimento da Agricultura familiar - PRONAF, e o Governo Federal criou a Lei nº11.947/2009, a qual obriga a aquisição de produtos através do Programa Nacional de Alimentação Escolar -PNAE, e o Programa e o Programa de Aquisição de Alimentos - PAA. Estes contribuem para a segurança alimentar saudável e sustentável, atendendo às necessidades nutricionais desse público (BRASIL,2016; BEVILAQUA, 2016).

Outo aspecto necessário para melhorar a sustentabilidade, tanto para os agricultores, quanto para a sociedade em geral, é a educação, que implementa a capacidade de desenvolver a conscientização, em especial das futuras gerações, que são as crianças (REIS; LIMA; DESIDERIO, 2018).

Neste sentido, os agricultores necessitam de uma atenção especial, para que permaneçam no campo, com políticas públicas, e educação que desperte a sensibilidade e 
responsabilidade ambiental, promovendo a qualidade de vida (REIS; LIMA; DESIDERIO, 2018).

Este estudo bibliográfico pressupõe uma reflexão sobre as estratégias necessárias à implementação da Agricultura familiar no Brasil, de forma sustentável, produzindo alimentos necessários, de qualidade e, combinando produtividade, com reordenamento econômico e social, educacional, além de se evitar, da melhor forma possível, a agressão ao meio ambiente.

\section{Desenvolvimento}

\subsection{Desenvolvimento da Agricultura no Brasil}

O Brasil a partir da década de sessenta, iniciou um processo de modernização da agricultura, incentivada pelos países desenvolvidos, e para isso estimulava a mecanização, utilização de adubos químicos, sementes hibridas selecionadas para melhor produtividade, uso do agrotóxico para a prevenção de pragas e ervas daninhas, e ainda melhorou as linhas de créditos, com o intuito de aumentar a produção agrícola, para o mercado externo, tendo como foco as grandes propriedades rurais(NAVOLAR; RIGNON; PHILIPPI, 2009; FROTA; OLIVEIRA; COSTA, 2017).

A agricultura de subsistência, ficou fora do desenvolvimento, sem políticas que amparassem essa parcela fundamental de trabalhadores. $O$ pequeno produtor rural, da agricultura de subsistência passou a ser visto como inferior, e ultrapassado, devido às tecnologias utilizadas pela agricultura de grande extensão. Desta maneira, perderam espaço no cenário da produção, fazendo com que muitos agricultores abandonassem a atividade no campo, em busca de melhores oportunidades de trabalho na cidade, causando o êxodo rural, e sobretudo originando mais desigualdade social (VIEIRA; IZA; KORZ; FISCHER,2018).

Recentemente, os olhares da sociedade voltaram-se para a agricultura de pequenas propriedades, levantando muitos aspectos relevantes e necessários para que possam assegurar a sustentabilidade e fixação do trabalhador no campo. Os agricultores lutam para sobreviver e tornar estas propriedades economicamente sustentáveis nesse mercado globalizado, com economia agressiva e falta de oportunidades, libertando-se do êxodo rural. Estas propriedades produzem alimentos para o consumo da população, saudáveis e com benefícios ao meio ambiente, tendo em vista que causam menor impacto ambiental.

\subsection{Reconhecimento da Agricultura Familiar}

Na década de 90, o poder público reconheceu a importância do papel do pequeno produtor, com o decreto Lei $\mathrm{n}^{\circ} 1.946$, no ano de 1995, com a criação do Programa Nacional 
de Agricultura Familiar (PRONAF). Este programa fornece recursos para o pequeno produtor investir na propriedade, para o desenvolvimento do agronegócio, com as menores taxas de juros do mercado. O agricultor pode utilizar os recursos que são exclusivamente para essa categoria em compra de sementes, equipamentos, maquinários ou fazer melhorias na infraestrutura da propriedade (BRASIL, 2016; BEVILAQUA, 2016).

Agricultura familiar teve o marco legal ao ser definida e reconhecida legalmente pela Lei 11. 326/2006 (BRASIL,2006), como a atividade desenvolvida pelos agricultores na área rural e que possuem propriedade de até quatro módulos fiscais, o que representa 72 hectares para o município de Serranópolis do Iguaçu-PR, e na qual utilizam mão de obra do próprio núcleo familiar, bem como a maior parte da renda ser proveniente da produção rural (BRASIL, 2006). Essa agricultura de subsistência é responsável por mais de $70 \%$ da alimentação produzida no Brasil (LIMA; SILVA; IWATA, 2019) e de igual importância para a alimentação no âmbito mundial, e a mesma é realizada em menor extensão e se destaca como a base econômica de $90 \%$ dos pequenos municípios de até vinte mil habitantes.

O debate sobre a relevância da agricultura familiar, na produção de alimentos e desenvolvimento da economia sustentável, tem conseguido apoio de diversos setores da sociedade (BEZERRA; SCHLINDWEIN, 2017). Esta forma de cultivo, utiliza maquinário em menor escala, sendo assim, com menor impacto ambiental, e desperdício de recursos naturais. Contudo, ao se desenvolver, implementa também a agricultura sustentável, que atende às necessidades de produção de alimentos, e preserva a biodiversidade, utilizando a terra com o menor prejuízo possível.

\subsection{Agriculturas Sustentáveis}

Desenvolvimento sustentável foi usado pela Organização das Nações Unidas (ONU), no estudo sobre mudanças climáticas, devido à problemática ambiental, com o intuito de corrigir os riscos e estimular o desenvolvimento com menor impacto ao meio ambiente e de finalidade preventiva. Este estudo foi utilizado para se referir a atividade agrícola desenvolvida em harmonia e cuidados com os recursos naturais. Esse equilíbrio é essencial para a permanência da vida humana neste planeta com saúde, qualidade e dignidade (BEVILAQUA, 2016).

Tudo está sendo globalizando, porém esta valorização da sustentabilidade é urgente para que seja essencial aos valores mundiais, a fim de se resgatar os recursos ambientais para nossos filhos, netos e gerações futuras.

A agricultura sustentável precisa atender às necessidades básicas dos seres humanos 
(água, alimentos, combustíveis, roupas, proteção), a fim de ter, abrigo, dignidade e liberdade, nas gerações existentes e para as futuras (AMARAL; ARAÚJO, 2015). Esta perspectiva precisa ter um novo foco, nas relações humanas, ligada à solidariedade, cooperação, colocando também mulheres, como protagonistas neste processo de mudanças (VIEIRA; IZA; KORZ; FISCHER, 2018).

Com habilidade feminina, as mulheres agricultoras abraçam os desafios, como por exemplo, de algo novo como a sustentabilidade, e vem colocando em ação os ensinamentos e conhecimentos transmitidos de geração à geração, diversificando a produção da propriedade, colocando em foco a sua manutenção com a produção de alimentos, fortalecendo a sua autonomia e empoderamento. Esta sustentabilidade permeia os aspectos social, ambiental e econômico. O empreendedorismo feminino vem ao encontro de uma qualidade de vida da família e o viver em harmonia com o meio ambiente (VIEIRA; IZA; KORZ; FISCHER, 2018).

A agricultura sustentável aparece como foco à agricultura familiar, trazendo uma pressão da sociedade, por produção que conserve os recursos naturais, forneça alimentos saudáveis e de qualidade nutricional, entretanto que não ameace o meio ambiente, a saúde, o desenvolvimento tecnológico, a segurança alimentar, garantindo os direitos básicos do ser humano (BEVILAQUA, 2016).

A sociedade depara-se diante de um grande desafio de resgatar a viabilidade da agricultura familiar, melhorando a produção, sem ignorar as tecnologias, protegendo os recursos naturais. Neste sentido, é necessário se evitar o empobrecimento do solo, cuidar da biodiversidade, conservar a qualidade da água, do ar e garantindo a viabilidade da propriedade, com qualidade de vida dos trabalhadores, tornando-a atrativa às novas gerações, principalmente fixando os jovens no campo, preservando a cultura local que resguarda a natureza e o desenvolvimento da comunidade, evitando o temível êxodo rural (BEVILAQUA, 2016).

Inegavelmente que a agricultura familiar precisa ser fortalecida e ampliada com o apoio de políticas públicas, que afirmam o comprometimento com a sustentabilidade no âmbito socioeconômico e ambiental. Esta modalidade agrícola, é responsável em gerar mão de obra e alimentos saudáveis aos agricultores e responsável pela segurança alimentar do país, entretanto, necessita de se tornar o foco das atenções da sociedade.

Para enfrentar este cenário de desvalorização em que se encontra a agricultura familiar, a Organização das Nações Unidas- ONU, lançou de 2019 a 2028 um programa intitulado como "Década das Nações Unidas para a Agricultura Familiar", com o objetivo de 
impulsionar a elaboração de políticas públicas, que promovam o desenvolvimento permitindo a sustentabilidade e a preservação do meio ambiente (DA SILVA, 2019).

Desta forma, oportuniza discussões sobre a realidade, as necessidades e a importância da agricultura familiar, que tanto contribui para a alimentação no mundo (FRATARI; DA SILVA, 2019).

Convém ressaltar que a sustentabilidade exige ações imediatas e urgentes e de forma coletiva, sendo mister o uso da ferramenta poderosa para conscientização, que é a educação. Os professores são formadores de opinião, neste sentido, de grande importância para a construção de uma consciência direcionada para a sustentabilidade ambiental. Este trabalho precisa ser organizado nas redes de ensino, em todas as etapas de escolaridade, sendo de suma importância que se inicie o mais cedo possível, envolvendo as crianças na formação de opinião a respeito do cuidado com a preservação e conservação dos recursos naturais (REIS; LIMA; DESIDERIO,2018). Desta forma, as políticas educacionais devem evidenciar a sensibilização para uma consciência planetária, onde todos terão a oportunidade de aprender valores, comportamentos e modos éticos de vida, necessários para um futuro sustentável, em especial às futuras gerações de agricultores familiares.

\subsection{Discussão}

\subsubsection{Sustentabilidade e qualidade de vida}

O estudo e o uso da palavra sustentabilidade tem gerado inúmeras pesquisas e discussões, tanto no meio acadêmico, quanto na sociedade de modo geral, no Brasil e principalmente entre as nações de maior desenvolvimento, classificadas como de primeiro mundo.

A palavra sustentabilidade, deriva do verbo sustentar que vem do latim, sustentare, que significa conservar, amparar, defender, manter (BEVILAQUA,2016).

Esse termo refere-se aos cuidados com um mundo não visto por partes, e sim como um ambiente ecológico na totalidade, onde acontecem as relações sociais, a produção, o desenvolvimento tecnológico a todo vapor. Neste sentido, há a necessidade de se analisar o significado da palavra num sentido mais amplo contudo, sem omitir o que afeta o ser humano, como por exemplo a saúde, lazer, trabalho educação, política, economia, fatores aliados aos recursos naturais.

As agressões ao meio ambiente realizados em qualquer lugar do mundo proporcionam consequências em âmbito global. Obviamente, que para haver mudança, faz-se necessário alterar o enfoque de prosperidade econômica, para um desenvolvimento que preserve ao 
máximo os recursos ambientais, o desenvolvimento sustentável, a ética nas ações humanas em relação à natureza (BEVILAQUA, 2016).

Neste sentido, a sustentabilidade precisa estar baseada nas relações sociais de trabalho e produção, econômica e ambiental.

Certamente que ao trazer como foco esse assunto, é necessário apresentar outra temática que é a produção de alimentos, necessária para a sobrevivência da humanidade. Como alimentar quase oito milhões de pessoas, tendo com o eixo principal o respeito com o meio ambiente, e ser economicamente viável, é um dilema a ser contextualizado.

Sem dúvida, os atores sociais principais neste cenário são os pequenos produtores rurais, ou seja, os representantes da agricultura familiar. Evidentemente que há a necessidade de aumentar a produção de alimentos, para promover a segurança alimentar, porém com o foco mantendo na preservação dos recursos naturais, respeitando-se o meio ambiente, através do cultivo e produção de forma ética e responsável, no que tange o ecossistema.

\subsubsection{A Contribuição da Agricultura Familiar para a Sustentabilidade}

A agricultura familiar é uma atividade capaz de aumentar a produção de alimentos, e ser economicamente viável, com práticas responsáveis com o meio ambiente, tendo mercado crescente aos produtos saudáveis e frescos, fornecidos diretamente dos produtores. Esta prática incorpora os fatores econômicos, sociais e ambientais, por ser desenvolvida pelo núcleo familiar, e considera a terra como um bem comum dos membros, utilizada para atender as suas necessidades, valorizando a diversidade, utilizando a policultura, distribuindo com equilíbrio os espaços, gerando qualidade de vida (RIBEIRO, 2017).

Vale ressaltar que ao se desenvolver e fortalecer a agricultura familiar, estar-se-á fortalecendo a sustentabilidade do meio ambiente, os agricultores, e a sociedade local, regional e do país (RIBEIRO, 2017).

Dada à importância desta atividade de produção, para a segurança alimentar e sustentabilidade dos recursos naturais, torna-se urgente um envolvimento dos diversos setores da sociedade e como principal foco, o poder público, viabilizando ações voltadas às pequenas propriedades rurais, para se evitar o abandono do campo, causando o êxodo rural e maiores problemas sociais na área urbana. Verifica-se que a falta de estímulo à continuidade familiar/sucessão, pode causar esvaziamento do campo, devido aos jovens, filhos de agricultores, almejarem novas perspectivas nos grandes centros (POTRICH; GRZYBOVSKI; TOEBE, 2016).

Neste cenário em que a mulher vem participando de todos os aspectos da sociedade, e 
buscando seu empoderamento e seu espaço como protagonista, há necessidade de reconhecer e valorizar seu trabalho e sua vida, a fim de lhe proporcionar autonomia, autoestima no direcionamento de mudanças, onde prevaleça a qualidade de vida e a sustentabilidade na produção. Estas mudanças na vida de quem sempre foi submissa, ocorrerão a partir do conhecimento, e reconhecimento de sua importância na efetivação de novos paradigmas de produção (VIEIRA; IZA; KORZ; FISCHER, 2018). Nota-se que as mulheres despontam com algo novo, rompendo os padrões vigentes, e se destacando como empreendedoras rurais, valorizando os saberes compartilhados através de gerações, promovendo mudanças, confrontando com a produção convencional (VIEIRA; IZA; KORZ; FISCHER,2018), melhorando sua independência e contribuindo para uma nova forma de produzir, utilizando sensibilidade e criatividade feminina.

Sem dúvida que a Organização das Nações Unidas - ONU oportuniza a sociedade, analisar, pesquisar e apoiar a agricultura familiar reconhecendo sua importância, declarando a Década da Agricultura Familiar de 2019 a 2028. Espera-se que os líderes mundiais adotem políticas de apoio a estes trabalhadores do campo, que norteiem um novo sistema de alimentação e desenvolvimento rural sustentável. Neste sentido, urge que o objetivo não seja somente a produção, mas que sejam contemplados os aspectos socioeconômicos, bem como a sustentabilidade dos recursos naturais (SILVA, 2019).

\subsubsection{Políticas Públicas para a Agricultura Familiar}

O Brasil destaca-se na formulação de políticas públicas, para o incentivo e fortalecimento da agricultura familiar, para o desenvolvimento rural, aumentando a produtividade de maneira sustentável, e que reflita na melhoria da qualidade de vida dos produtores, do meio ambiente e o fornecimento de produtos saudáveis aos consumidores. Para tanto são necessários investimentos, a abertura de financiamentos, acesso às novas tecnologias, bem como a implementação do conhecimento, e por conseguinte a aprendizagem por meio de suporte técnico, para melhorar a gestão e ampliar os mercados para a comercialização dos produtos (BOJANIC, 2017).

O Governo Federal criou o Programa Nacional de Fortalecimento da Agricultura Familiar (PRONAF), como incentivo às linhas de crédito para proporcionar financiamentos aos pequenos agricultores. Concebe-se que este Programa está contribuindo para o aumento da produtividade, e melhorar a renda das famílias (BEVILAQUA, 2016).

Outros programas que tem se tornado referência são o Programa de Aquisição de Alimentos (PAA), e o Programa Nacional de Alimentação Escolar (PNAE), onde 
obrigatoriamente $30 \%$ dos recursos repassados pelo Fundo Nacional de Desenvolvimento da Educação (FNDE), devem ser aplicados na aquisição de gêneros alimentícios provenientes da agricultura familiar. Com estes programas, o governo garante mercado estável para os produtores, em seu próprio município e região, contribuindo para a economia local. Estes programas têm se destacado e apontados como exemplos a outros países (RIBEIRO; PEREIRA, 2015; BRASIL, 2016).

A Lei $n^{\circ} 11.947 / 2009$, que obriga a compra dos produtos da agricultura familiar, representa um ato de pioneirismo e de avanço, para ofertar aos estudantes no mínimo uma alimentação diária de qualidade, e a contrapartida governamental vem a subsidiar a aquisição dos gêneros para aplicação na área de ensino. O programa contribui para o aumento da renda dos produtores locais, melhorando a qualidade de vida de suas famílias, evitando-se o êxodo rural, promovendo o desenvolvimento socioeconômico do município.

Esta política de estímulo, tem impacto positivo na alimentação das crianças e adolescentes da rede pública, destacando-se que para uma parcela considerável de alunos, esta é a refeição mais importante do dia (RIBEIRO; PEREIRA, 2015; BRASIL, 2016). Estes alimentos são mais saudáveis, naturais, frescos, diversificados, e contribuem para uma alimentação equilibrada. Ressalta-se que a alimentação escolar tem importante papel no crescimento e no rendimento escolar (LIMA; SILVA, 2016). Um aluno bem nutrido apresenta um potencial intelectual melhor ((RIBEIRO; PEREIRA, 2015). Estas escolas da rede pública, atendem alunos mais vulneráveis na questão econômica, e que apresentam necessidades nutricionais (BRASIL, 2006). Com os neurônios bem nutridos, aumenta a capacidade cerebral, melhorando as funções cognitivas como a atenção, memorização, concentração, e o raciocínio, fatores imprescindíveis para uma aprendizagem melhor (RIBEIRO; SILVA, 2013). A Lei ${ }^{\circ} 11.947 / 2009$ permitiu aos alunos das escolas públicas aumentar o rendimento escolar, e ter expectativa de uma vida melhor, e poder usufruir de uma alimentação saudável, atendendo aos preceito da segurança alimentar, sustentável(RIBEIRO; PEREIRA, 2015).

Para a organização de uma sociedade responsável ambientalmente, a nível nacional e mundialmente, o caminho é a ênfase na educação dos cidadãos. Ressalta-se que a educação é prioridade, na efetivação de uma proposta socialmente e economicamente correta, em relação ao meio ambiente. Os conceitos de busca e luta por uma sociedade responsável vão sendo inseridos, e transformando e rompendo os antigos paradigmas de desenvolvimento (REIS; LIMA; DESIDERIO, 2018). 


\section{Considerações Finais}

Quando se reflete sobre o desenvolvimento sustentável, precisa-se lembrar que sua extensão ultrapassa os cuidados com o meio ambiente, pois. abrange ainda as relações sociais, políticas, culturais e econômicas, no dia a dia das pessoas, bem como com as gerações futuras. O homem possui as necessidades básicas de sobrevivência, para tanto produz com seu trabalho e consome bens, entretanto, nem sempre se preocupa com o equilíbrio do ecossistema. Uma das necessidades básicas e essenciais é a produção de alimentos, sendo também uma preocupação mundial, onde uma parcela da sociedade não possui a alimentação necessária.

Durante muito o poder público se preocupou em ofertar linhas de crédito para agricultura de grande extensão. Estas políticas econômicas iniciaram uma revolução, em que o meio ambiente não era considerado, devido ao exagero na obtenção do lucro, com a produção para exportação. As pequenas propriedades rurais esquecidas, e sem apoio, ou políticas de incentivo, com o passar do tempo devido o abandono, tornaram-se inviáveis. Com esse descaso, muitas famílias venderam suas propriedades para alcançarem melhores condições nas cidades, ocasionado com esta mudança drástica, um problema nas áreas urbanas.

Aos poucos, a atenção voltou-se para a agricultura familiar, que além de ser a responsável pela produção da maior parte dos alimentos, também contribui para a conservação do meio ambiente. Neste sentido, o Brasil criou algumas políticas de apoio, como por exemplo a Lei 11.947/2009, que representa um ato de pioneirismo e de avanço, para ofertar aos estudantes no mínimo uma alimentação diária de qualidade, e a contrapartida governamental, vem a subsidiar a aquisição dos gêneros para aplicação na área de ensino, o que obriga os municípios a investirem na aquisição de gêneros alimentícios da agricultura familiar.

A obrigatoriedade da aquisição de alimentos da agricultura familiar local, possibilitou às crianças e adolescentes da Educação Básica das escolas públicas, uma alimentação equilibrada, respeitando-se as necessidades nutricionais desta faixa etária, promovendo a sua segurança alimentar, ou seja uma alimentação sustentável, para que possam ter um adequado desenvolvimento físico, fisiológico e intelectual.

O diferencial dos alimentos é o fato de possuírem o valor nutricional necessário e fundamental ao bom desempenho na aprendizagem, pois aumenta a capacidade cerebral, melhorando a atenção, memorização, concentração e o raciocínio, imprescindíveis para a aprendizagem. Esta lei permitiu aos alunos das escolas públicas aprimorarem o seu 
rendimento escolar e terem uma expectativa de futuro promissor e valorizarem a agricultura familiar, conhecendo e respeitando o nobre trabalho dos pequenos produtores e seus familiares.

Com a mudança de paradigmas no conceito de qualidade de vida e sustentabilidade, a sociedade voltou-se para o foco na preservação ambiental. E surge o grande questionamento, de como se deve preservar os recursos naturais, com a eminente falta de alimento no mundo. Sem dúvida, os estudos e análises das autoridades e cientistas, demonstraram que a agricultura familiar é essencial para a produção de alimentos saudáveis e necessários para a segurança alimentar mundial, com práticas educacionais e conscientes, que preservam o meio ambiente e a biodiversidade.

Neste sentido com a necessidade global de se aumentar a produção de alimentos, de uma forma que cause o menor prejuízo ao meio ambiente e erradicar a fome, a ONU vê a necessidade de despertar a atenção e o foco das autoridades internacionais, nacionais, locais, bem como da sociedade, para a importância da agricultura familiar no enfrentamento desta problemática eminente.

Ao se oficializar o Programa 2019 A 2028 o decênio da agricultura familiar, motivada pela iniciativa da ONU, coloca-se uma perspectiva de elaboração de políticas públicas, a fim de se alcançar os objetivos direcionados para o aumento da produção de alimentos, suficientes e acessíveis para toda população mundial, garantindo a segurança nutricional, e cumprindo os objetivos da ODS da agenda 2030. Além disso, estas ações fortalecem a economia local, e promovem a justiça social no campo, que por muito tempo ficou negligenciada, de forma que o foco central seja a preservação sustentável dos recursos naturais, e consequentemente a vida humana, promovendo desta maneira a educação ambiental e a conscientização do homem para a execução de práticas adequadas.

Desta forma, é imprescindível que o poder público, além de criar políticas de fortalecimento e mercado seguro para a comercialização dos produtos, precisa se preocupar com a educação, dos agricultores e seus familiares, voltada para a responsabilidade ambiental. Tornando-os cidadãos, conscientes de suas ações, despertando a sensibilidade ecológica, para um desenvolvimento sustentável, tendo a visão de humanidade e não somente lucratividade.

De acordo com este cenário, há a necessidade de estabelecer conceitos inovadores, hábitos novos, diferentes perspectivas, o bem estar e qualidade de vida, levando em conta o desenvolvimento econômico sustentável, bem como a implementação do respeito pelos recursos naturais, com a visão de que são essenciais à sobrevivência da humanidade sob o ponto de vista físico, fisiológico, econômico e psicossocial. 
A Década se fundamentou em uma visão de um mundo onde todos tivessem a oportunidade de se beneficiar da educação e de aprender valores, comportamentos e modos de vida exigidos para um futuro sustentável visando uma transformação positiva das sociedades a nível local, regional e global. As suas dimensões perpassaram por questões de natureza educativa, ambiental, social, econômica e política que fossem capazes de promover melhorias e tornar os diferentes sujeitos participativos nos processos de escolhas e tomadas de decisões.

Enfatiza-se que o Brasil participa do grupo de países associados, composto pela Rússia, Índia, China e África do Sul, denominado de BRICS, no qual, todos são classificados como emergentes pela ONU, e realizam programas de desenvolvimento da agricultura familiar em seu território. O Brasil participa deste grupo, junto com os demais, os quais realizam comércio entre si, e por consequência, há o fortalecendo do superávit da balança comercial, para a expansão da agricultura familiar, tornando-a indispensável para a segurança alimentar sustentável e econômica destes países, o que incide sobre a sua soberania.

Há o entendimento de que a agricultura familiar é essencial para o desenvolvimento renovável da área rural. Portanto, os investimentos que o Governo Federal já realiza, necessitam ser ampliados, para fortalecer cada vez mais a atividade agrícola de suma importância para o Brasil, enquanto um país emergente, melhorando a qualidade de vida de seus diversos atores sociais que compõem a sociedade.

\section{Referências}

AMARALA Adriana Queiroz do; ARAÚJO, Elvira Aparecida Simões de. Agricultura Familiar de Sustentabilidade: uma Análise da Produção Científica da Embrapa. Universidade de Taubaté e Faculdade Pitágoras de Imperatriz. São Paulo e Maranhão. Publicado na Rev. Cienc. Gerenc., v. 19, n. 29, p. 47-50, 2015. Disponível em: file://C:/Users/User/Downloads/2986-Texto\%20do\%20artigo-11397-1-10-

20150827\%20(1).pdf. Acesso em: 28/07/20.

AZEVEDO, E; RIGON, S. A. Sistema alimentar com base no conceito de sustentabilidade. In: TADDEI, J. A.; LANG, R. M. F.; SILVA, G. L.; TOLONI, M. H. A. Nutrição em saúde pública. São Paulo: Rubio, 2010. p. 543-560.

BRASIL. Fundo Nacional de Desenvolvimento da Educação (FNDE). Conselho Deliberativo. Resolução FNDE CD no 032, de 10 de agosto de 2006. Estabelece as normas para a execução do Programa Nacional de Alimentação Escolar (Pnae). 2006. Disponível em: http://www.fnde.gov.br>. Acesso em 21 de maio de 2020.

BRASIL. Presidência da República. Casa Civil. Lei n 11.947, de 16 de junho de 2009 dispõe sobre o atendimento da alimentação escolar e do Programa Dinheiro Direto na Escola aos alunos da educação básica. Disponível em: 
http://www.planalto.gov.br/ccivil_03/_Ato2007-2010/2009/Lei/L11947.htm >. Acesso em 12 de maio de 2020.

BRASIL. Ministério da Educação. Fundo Nacional de Desenvolvimento da Educação FNDE. Aquisição de produtos da agricultura familiar para a alimentação escolar. 2. ed. Brasília: FNDE, 2016. Disponível em: https://www.fnde.gov.br/programas/pnae/pnae-areagestores/pnae-manuais-cartilhas/item/8595-manual-de-aquisi\%C3\%A7\%C3\%A3o-deprodutos-da-agricultura-familiar-para-a-alimenta\%C3\%A7\%C3\%A3o-escolar. Acesso em: 12 de maio de 2020.

BEVILAQUA, Karen Affonso. Pensando Além Da Produção: Uma Análise Da Agricultura Familiar Como Ferramenta De Consolidação Da Sustentabilidade Pluridimensional E Da Segurança Alimentar. Universidade Estadual Paulista Júlio de Mesquita Filho, $\quad$ Franca, 2016. Disponível em: repositorio.unesp.br/bitstream/handle/11449/148615/bevilaqua_ka_me_fran.pdf?sequence=3. Acesso em: 29/07/20.

BEZERRA, Gleicy Jardi; SCHLINDWEIN, Madalena Maria. Agricultura familiar como geração de renda e desenvolvimento local: uma análise para Dourados, MS, Brasil. Revista une analyse à Dourados, MS, Brésil Agricultura familiar, Dourados, MS, Brasil. DOI: http://dx.doi.org/10.20435/1984-042X-2016-v.18-n.1(01). Disponível em: www.scielo.br/pdf/inter/v18n1/1518-7012-inter-18-01-0003.pdf. Acesso em: 27/07/20.

BOJANIC, Alan. Iniciativa regional da FAO aponta agricultura familiar como promotora do desenvolvimento rural sustentável e a agenda 2030. Publicado em 13/10/2017, Organização Das Nações Unidas. FAO. Disponível em: fao.org/brasil/noticias/detail-events/pt/c/1043666/. Acesso em 26/07/20.

CRUZ, Fernanda. Década da agricultura familiar pode mudar o futuro global. Asa Brasil, 31/09/19. Disponível em: https://agroecologia.org.br/2019/05/31/decada-daagriculturafamiliar-pode-mudar-o-futuro-global/. Acesso em 20/06/20.

DOS SANTOS, A.M.; MITJA, D.; Agricultura familiar e desenvolvimento local: os desafios para a sustentabilidade econômico-ecológica na comunidade de Palmares II, Parauapebas. PA .Interações, 2016, Campo Grande, v. 13, n. 1, 2016. Disponível em: /centrodeestudoseassessoria.org.br/comeca-oficialmente-a-decada-da-agricultura-familiardas-nacoes-unidas/. Acesso em 12/06/20.

ELIAS, Lilian de Pellegrini; BELIK, Walter; ODERICH, Edmundo Hoppe. A construção de um sistema alimentar sustentável e a agricultura familiar. IX Seminário Internacional sobre Desenvolvimento Regional, Processos, Política e Transações Territoriais, Santa Cruz do Sul, Rio Grande do Sul, 2019. Disponível em: file://C:/Users/User/Downloads/194061192617324-1-PB.pdf. Acesso: 15/06/20.

ENNIS, Rocío; NIETO, Daniela Patricia; SFICH, Vivian Mariel. Hacia un modelo productivo alternativo al hegemónico: el casode los productores hortícolas del Partido La Plata. XXI Jornadas de Geografía de la UNLP, 9 a 11 de outubro de 2019, Ensenada, Argentina.Disponívelem:http://www.memoria.fahce.unlp.edu.ar/trab_eventos/ev.13539/ev.13 539.pdf. Acesso em: 12/06/20. 
FANTELI, Dreisse Gabbi; FERREIRA, Aline Guterres; TONETTO, Cristiane Maria; BELING Helena Maria. A agricultura familiar e suas estratégias de sobrevivência. Dissertação de Mestrado - Universidade Federal de Santa Maria, Estado do Rio Grande do Sul, Santa Maria, 2019. Disponível em: /www2.faccat.br/portal/sites/default/files/fantineli_ferreira_godoy_beling.pdf. Acesso em $12 / 06 / 20$.

LIMA, Antônia Francisca; SILVA, Edvânia Gomes de Assis; IWATA, Bruna de Freitas. Agriculturas e agricultura familiar no Brasil: uma revisão de literatura. Revista Retratos de Assentamentos, v. 22, $\mathrm{n}^{\mathrm{o}} .1$, p.50-68, 2019, ISSN: 1516-8182, doi: i: $10.25059 / 2527-$ 2594/retratosdeassentamentos/2019.v22i1.332. https://www.researchgate.net/publication/334268386_Agriculturas_e_agricultura_familiar_no _Brasil_uma_revisao_de_literatura. Acesso em 15/06/20.

MARIAN, Marcia Gilmara; IZA, Oscar Benigno; KORZ, Camila; FISCHER, Jocimar. Agricultura sustentável: favorecendo ambientes saudáveis e o empoderamento feminino. Publicado em Rev. Ed. Popular, Uberlândia, v. 18, n. 2, p. 4-25, maio/ago. 2019, DOI: https://doi.org/10.14393/REP-v18n22019-46405.

Disponível

em: file://C:/Users/User/Desktop/agricultura $\% 20 \mathrm{e} \% 20 \mathrm{o} \% 20 \mathrm{empreendedorismo} \% 20 \mathrm{feminino.pdf}$. Acesso em: 28/07/20.

NAVOLAR, T. S.; RIGON, S. A.; PHILIPPI, J. M. S. Diálogo entre agroecologia e promoção da saúde. Revista Brasileira em Promoção da Saúde, Fortaleza, v. 23, n. 1, p. 6979, jan./mar. 2010. Doi: 10.5020/18061230.2010.p69.

ORGANIZAÇÃO DAS NAÇÕES UNIDAS. ONU. Agricultura Familiar e Sustentabilidade. DA SILVA, Jose Grazino, Estado de São Paulo, 14/06/19. Disponível em: https://nacoesunidas.org/artigo-agricultura-familiar-e-sustentabilidade/ . Acesso em 14/06/20

ORGANIZAÇÃO DAS NACÕES UNIDAS. ONU. Agricultores familiares são essenciais para subsistência global, diz oficial da ONU. Publicado em 29 de maio de 2019. Disponível em: https://nacoesunidas.org/agricultores-familiares-sao-essenciais-para-subsistencia-globaldizoficial-da-onu/. Acesso em: 25/05/20.

ORGANIZAÇÃO DAS NAÇÕES UNIDAS. ONU. Década da Agricultura Familiar: Carta aberta de Julio Berdegue, representante regional da FAO. FAO, Publicado em 27 de agosto 2019. Disponível em: http://www.fao.org/brasil/noticias/detailevents/pt/c/1206221/. Acesso em: 11/06/20.

ORGANIZAÇÃO DAS NAÇÕES UNIDAS. ONU. Agricultores familiares são essenciais para subsistência global. Publicado em 29/05/2019, atualizado em 14/11/2019. Disponível em: https://nacoesunidas.org/agricultores-familiares-sao-essenciais-para-subsistencia-globaldiz-oficial-da-onu/. Acesso em: 26/07/20.

PILLADO-ALBARRÁN,Karla Violeta; RAMÍREZ-HERNÁNDEZ, Javier Jesús; AVITIARODRÍGUEZ Jessica Alejandra. Acesso à comida: um contraste de visões. Ano 5, Número 9, janeiro a junho de 2020. Revista CoPaLa. Pp 101-124. ISSN: 2500-8870. Disponível em: http://www.revistacopala.com/DOI: 10.35600.25008870.2020.9.00161. Acesso em: 11/06/20. 
POTRICH, Rafaele; GRZYBOVSK, Denize; TOEBE, Carlisa Smoktunowicz. Sustentabilidade nas pequenas propriedades rurais: um estudo exploratório sobre a percepção do agricultor. Publicado em v. 25 n. 1: Estudos Sociedade e Agricultura, fevereiro a maio de 2017, DOI: https://doi.org/10.36920/esa-v25n1-9. Disponível em file:///C:/Users/User/Downloads/826-Texto\%20do\%20artigo-2538-1-1020170424\%20(1).pdf. Acesso 28/07/20.

RIBEIRO, Mariana Emidio Oliveira. Alternativas De Adoção De Práticas No Âmbito Do Desenvolvimento Sustentável Em Propriedades Rurais Familiares. Universidade do Vale do Taquari - UNIVATES. Lajeado, Rio Grande do Sul, dezembro de 2017. Disponível: /www.univates.br/bdu/bitstream/10737/2144/1/2018MarianaEmidioOliveiraRibeiro.pdf.

Acesso: 29/07/20.

RIBEIRO, A. C. L. A.; PEREIRA, D.D. Alimentação Escolar E Sua Contribuição Para Uma Educação De Qualidade. In: VII Fórum Internacional de Pedagogia, 4, 2015, Campina Grande. Anais...Campina Grande: Editora Realize, 2015, p.1-12.

SILVA, F. R. F. Gênero, agroecologia e economia solidária: estudo de caso do grupo de mulheres do Acampamento Recanto da Natureza em Laranjeiras do Sul-PR. DMA, Curitiba, v. 39, p. 115-132, 2016. Doi: doi.org/10.5380/dma.v39i0.45697. Acesso: https://revistas.ufpr.br/made/article/view/45697. Acesso em 28/07/20.

SILVA, José Graziano. Agricultura familiar e sustentabilidade. Publicado em 14/06/2019 Atualizado em 14/06/2019, Organização Das Nações Unidas. FAO. Disponível em: nacoesunidas.org/artigo-agricultura-familiar-e-sustentabilidade. Acesso em 29/07/20.

REIS, Marlene Barbosa de Freitas; LIMA, Daniela da Costa Britto Pereira; DESIDERIO, Mônica. Desenvolvimento, educação e sustentabilidade: questões emergentes e desafiadoras. Publicado em Rev. Eletrônica Mestr. Educ. Ambient.Rio Grande, v. 35, n. 3, p. 4-22, set./dez.2018.E-ISSN 1517-1256. Disponível em: /Users/User/Downloads/7855-248451-PB.pdf. Acesso em 30/07/20. 